\title{
INDEX TO VOLUME 5
}

Andima, Susan J. See Larson, Roland E.

Beesack, Paul R. Bounds for Riemann-Stieltjes integrals, 75.

Berg, G., Julian, W., Mines, R. and Richman, F. The constructive Jordan curve theorem, 225.

Berkson, Earl and Rubel, Lee A. Seven different proofs that $L^{\infty} / H^{\infty}$ is not separable, 237.

Brown, Ron. Tamely ramified extensions of Henselian fields, 543.

Campbell, Douglas Michael. A survey of properties of the convex combination of univalent functions, 475.

Carroll, Robert. Some remarks on kernels, recovery formulas and evolution equations, 61.

Christiansen, Sarah L. M. Complete ergodicity, weak mixing and stacking methods, 79.

Clark, David C. Eigenvalue bifurcation for odd gradient operators, 317.

Clayton, Dennis. A reduction of the continuous homomorphism problem for $F$ algebras, 337.

Cooper, Wyatt G. and Hallam, Thomas G. Nonlinear perturbation of a linear system of differential equations with a regular singular point, 247.

Cutrer, Wayne. Some remarks on the slice algebra for $H^{\infty}, 255$.

Daverman, Robert J. On cells in Euclidean space that cannot be squeezed, 87.

Dolan, J. Michael and Klassen, Gene A. Dominance of $N$-th order linear equations, 263.

Edrei, Albert. The complete Padé tables of certain series of simple fractions, 559.

Fields, K. L. On the conjugating representation of a finite group, 345.

Fleischer, Isidore. On the interchange of order in repeated limits, 271.

Fletcher, Peter and Lindgren, William F. Some unsolved problems concerning countably compact spaces, 95.

Gehrmann, James E. and Sherman, Thomas L. Asymptotic behavior of solutions and their derivatives for linear differential equations, 275.

Gilmer, Robert. On polynomial and power series rings over a commutative ring, 157.

Gregory, John and Richards, Franklin. Numerical approximation for $2 m$-th order differential systems via splines, 107.

Gross, Fletcher. p-subgroups of core-free quasinormal subgroups II, 349.

Growney, J. A. S. Structure inherent in a free groupoid, 117.

Hallam, Thomas G. See Cooper, Wyatt G.

Heitman, R. C. and Levy, L. S. 1/1/2 and 2 generator ideals in Prüfer domains, 361.

Julian, W. See Berg, G.

Keener, M. S. On the equivalence of oscillation and the existence of infinitely many conjugate points, 125.

Kemper, John T. On the support of representing measures for harmonic functions, 375.

Kimberling, C. H. Some elementary number theoretic implications of the symmetric functions theorem, 283.

Klaasen, Gene A. See Dolan, J. Michael.

Krall, Allan M. The development of general differential and general differentialboundary systems, 493. 
Kuebler, Robin and Reid, J. D. On a paper of Richman and Walker, 585.

Landis, Dale and Morse, Marston. Tractions in critical point theory, 379.

Larson, Roland E. and Andima, Susan J. The lattice of topologies: a survey, 177.

Legg, M. W. and Walker, E. A. An algebraic treatment of algebraically compact groups, 291.

Leonard, Philip A. and Williams, Kenneth S. Jacobi sums and a theorem of Brewer, 301.

Levy, L. S. See Heitman, R. C.

Lindgren, William F. See Fletcher, Peter.

McLaughlin, T. G. Trees and isols, part I, 401.

Meister, Gary H. Almost periodic Dini theorems, 419.

Metzler, Richard C. Representation of ordered linear spaces, 427.

Mines, R. See Berg, G.

Moore, J. Douglas. On quasi-complete abelian p-groups, 601.

Morse, Marston. See Landis, Dale.

Reid, J. D. See Keubler, Robin.

Reynolds, A. On a Crank-Nicolson scheme for nonlinear parabolic equations, 611.

Richards, Franklin. See Gregory, John.

Richman, F. See Berg, G.

Rubel, Lee A. See Berkson, Earl.

Ryavec, C. Riemann's functional equation, 623.

Schochetman, I. and Wu, Y.-C. Continuity of stability groups and conjugation, 309.

Sherman, Thomas L. See Gehrmann, James E.

Silverman, H. Linear combinations of convex mappings, 629.

Singley, Donald H. Smoothness theorems for the principal curvatures and principal vectors of a hypersurface, 135.

Siwiec, Frank. Generalization of the first axiom of countability, 1.

van Lint, J. H. A survey of perfect codes, 199.

Walker, E. A. See Legg, M. W.

Whelen, Joseph A. Separable algebras over Prüfer domains, 145.

Williams, F. D. Homotopy-algebraic structures, 449.

Williams, Kenneth S. See Leonard, Philip A.

Wu, Y.-C. See Schochetman, I.

Zettl, A. Formally self-adjoint quasi-differential operators, 457. 